\title{
Tracking the Transcription Kinetic of SARS-CoV-2 in Human Cells by Reverse Transcription-Droplet Digital PCR
}

\author{
Ka-Ki Au ${ }^{1,+}$, Chunke Chen ${ }^{2,3,+}$, Yee-Man Chan ${ }^{1}$, Winsome Wing Sum Wong ${ }^{1}$, Huibin Lv ${ }^{4}$, \\ Chris Ka Pun Mok ${ }^{2,3, *}$ and Chun-Kin Chow ${ }^{1, *}$ \\ 1 Medtimes Molecular Laboratory Limited, Hong Kong, China; kitty@medtimes.com.hk (K.-K.A.); \\ ymchan@gmail.com (Y.-M.C.); wongwsw@hotmail.com (W.W.S.W.) \\ 2 The Jockey Club School of Public Health and Primary Care, Faculty of Medicine, \\ The Chinese University of Hong Kong, Hong Kong, China; chunkechen@cuhk.edu.hk \\ 3 Li Ka Shing Institute of Health Sciences, Faculty of Medicine, The Chinese University of Hong Kong, \\ Hong Kong, China \\ 4 HKU-Pasteur Research Pole, Li Ka Shing Faculty of Medicine, The University of Hong Kong, \\ Hong Kong, China; huibin01@connect.hku.hk \\ * Correspondence: kapunmok@cuhk.edu.hk (C.K.P.M.); isaac@medtimes.com.hk (C.-K.C.); \\ Tel.: + 852-37636128 (C.K.P.M.); +852-35896248 (C.-K.C.) \\ + Equal contribution.
}

check for updates

Citation: Au, K.-K.; Chen, C.; Chan, Y.-M.; Wong, W.W.S.; Lv, H.; Mok, C.K.P.; Chow, C.-K. Tracking the Transcription Kinetic of SARS-CoV-2 in Human Cells by Reverse Transcription-Droplet Digital PCR. Pathogens 2021, 10, 1274. https:// doi.org/10.3390/pathogens10101274

Academic Editors: Toshana Foster and Svetlana Khaiboullina

Received: 31 August 2021

Accepted: 29 September 2021

Published: 2 October 2021

Publisher's Note: MDPI stays neutral with regard to jurisdictional claims in published maps and institutional affiliations.

Copyright: (c) 2021 by the authors. Licensee MDPI, Basel, Switzerland. This article is an open access article distributed under the terms and conditions of the Creative Commons Attribution (CC BY) license (https:/ / creativecommons.org/licenses/by/ $4.0 /)$.

\begin{abstract}
Viral transcription is an essential step of SARS-CoV-2 infection after invasion into the target cells. Antiviral drugs such as remdesivir, which is used to treat COVID-19 patients, targets the viral RNA synthesis. Understanding the mechanism of viral transcription may help to develop new therapeutic treatment by perturbing virus replication. In this study, we established $28 \mathrm{ddPCR}$ assays and designed specific primers/probe sets to detect the RNA levels of 15 NSP, 9 ORF, and 4 structural genes of SARS-CoV-2. The transcriptional kinetics of these viral genes were determined longitudinally from the beginning of infection to $12 \mathrm{~h}$ postinfection in Caco- 2 cells. We found that SARS-CoV-2 takes around $6 \mathrm{~h}$ to hijack the cells before the initiation of viral transcription process in human cells. Our results may contribute to a deeper understanding of the mechanisms of SARS-CoV-2 infection.
\end{abstract}

Keywords: coronavirus; SARS-CoV-2; digital droplet PCR; transcription; subgenomic RNA

\section{Introduction}

There have been more than 179 million COVID-19 cases around the globe and nearly 4 million associated deaths since the initial disease outbreak in late 2019 [1]. The causative agent that is responsible for the disease is a new and emerging strain of coronavirus, namely SARS-CoV-2 [2,3]. SARS-CoV-2 belongs to the beta group of coronaviruses, which is in the family of Coronaviridae. The architecture of SARS-CoV-2 has been studied in detail [4]. Inside each virion, there is a positive sense, single-stranded viral genome which is around $30 \mathrm{~kb}$ long. Its genome encodes for four major structural proteins: spike (S), envelope (E), matrix (M), and nucleocapsid (N); sixteen nonstructural proteins (nsp1 to nsp16); and ten accessory proteins (ORF1a/1ab, 3a/b, 6, 7a/b, 8, 9b, and 10) [4].

SARS-CoV-2 mainly replicates in the human respiratory tract after infection [5]. After invading into the target cells, the SARS-CoV-2 virus initiates translation of two major replicase polyproteins, the pp1a (ORF1a) and pp1ab (ORF1ab) from the ORF region of its positive sense RNA genome. Most of the transcription- and translation-dependent proteins such as papain-like proteases, 3C-like protease, helicase, and RNA-dependent RNA polymerase are encoded at these regions [6]. Formations of the replication and transcription complex further drive the transcription of subgenomic mRNAs (sgRNAs) and new viral RNA genome. The sgRNAs are responsible for the production of various viral proteins. Other than the structural proteins, it is known that the nonstructural proteins (NSP) and the open reading frame (ORF) proteins are also essential during the 
replication process. At the late stage of replication cycle, the translated structural proteins are translocated into endoplasmic reticulum (ER)/Golgi and assembled into a virion with the newly produced genomic viral RNA. The virion is then finally released from the cell by exocytosis [7].

The entire replication cycle of a coronavirus takes more than ten hours [8,9]. Although some studies has sought to determine the transcriptional profile of SARS-CoV-2 at selected time points of postinfection, the kinetic of the viral transcription in human cells is still yet to be completely resolved [10-12]. Droplet digital PCR (ddPCR) is recently used to quantify low abundance of SARS-CoV-2 subgenomic viral gene transcripts by its advantage of low template requirementfor the reaction [13]. Ultra sensitive clinical diagnosis is one of the major applications of ddPCR, in such case the assay can identify the COVID-19 patients through detecting low expression of viral genes from their specimens [14]. However, the concern is that the primers and probes used for the current detection may not be updated promptly, as mutations are frequently identified from the new variants of SARS-CoV-2 [15]. In this study, we designed primers/probes sets for the ddPCR that target different viral genes of SARS-CoV-2. The ddPCR assays were then used to track the transcriptional kinetic of the 15 NSP, 9 ORF, and 4 structural genes of SARS-CoV-2 during the initial replication cycle in Caco-2 cells, which is a human cell line that is susceptible for the replication of SARS-CoV-2.

\section{Materials and Methods}

\subsection{SARS-CoV-2 Sequences and Alignment}

On 9 September 2020, 61,013 SARS-CoV-2 genome sequences were downloaded from GISAID, followed by MAFFT sequence alignment. Mutations from each viral gene were identified through the comparison to the sequence of BetaCoV/Hong Kong/VM20001061/2020 and 50 nucleotide positions with the highest mutation frequencies from each gene were determined. The viral gene mutation coordinates and their frequencies were annotated and summarized in Table S1, S2 and S3.

\subsection{Primers and Dual-Labeled Hydrolysis Probes}

All the primer oligos and dual-labeled fluorescent probes were synthesized and purified by Life Technologies and Sangon Biotech (Shanghai). Human ribonuclease subunit p30 (RNase P) was used to serve as our endogenous control.

\subsection{Viruses and Cells}

The SARS-CoV-2 virus strain (BetaCoV/Hong Kong/VM20001061/2020) was propagated in Vero E6 cells and the infectious titer of the viral stock was determined by serially diluting the virus on the Vero E6 cells by plaque-forming unit (pfu). All the experiments of virus culture were carried out in the biosafety level 3 containment facility in the University of Hong Kong and fully in accordance with the laboratory biosecurity and biosafety guidelines.

Human Caco-2 cell lines were purchased from ATCC and grown in a T-75 flask (Greiner Bio-One CELLSTAR, Austria) with Dulbecco's modified eagle medium (DMEM) that was supplemented with 10\% fetal bovine serum (FBS) (GIBCO, USA), 2 mM HEPES (Gibco), $100 \mathrm{U} / \mathrm{ml}$ of penicillin, $100 \mu \mathrm{g} / \mathrm{ml}$ of streptomycin, and 1\% of GlutaMax (Gibco, USA) and until 90\% confluency. Cells were then dissociated with trysin-EDTA (GIBCO, USA) and seeded into a 24-well tissue culture plate (TPP, Switzerland) at a concentration of $0.5 \times 10^{6}$ cells per well. Culture medium was then changed to $0 \%$ FBS-DMEM during and after the infection. All the cell cultures were incubated and grown at $37^{\circ} \mathrm{C}$ and maintained with $5 \% \mathrm{CO}_{2}$ in the incubator.

\subsection{Virus Infection and Collection of Cell Lysate}

Caco-2 cells were mock-infected or infected by SARS-CoV-2 at multiplicity of infection (MOI) of 0.01 . After $15 \mathrm{~min}$, the cells were either lysed by $350 \mu \mathrm{L}$ of RNA lysis buffer 
(Buffer RLT, Qiagen, Germany) after washed twice with pre-warmed $1 \times$ PBS $(\mathrm{T}=0)$ or further incubated for additional $45 \mathrm{~min}$. At 1-h postinfection (hpi), the cells were washed with pre-warmed $1 \times$ PBS and replaced with fresh cell-culture medium (DMEM, 0\% FBS). The infected cells were further incubated in $37^{\circ} \mathrm{C}$ incubator and the total RNAs were then harvested by the RNA lysis buffer at 2, 4, 6, 8, 10 and $12 \mathrm{hpi}$. All cell lysates were then kept at $-80{ }^{\circ} \mathrm{C}$ until RNA extraction.

\subsection{Preparation of $c D N A$ Templates}

Total RNAs were extracted from the cell lysates by using the RNeasy Mini Kit (QIAGEN, Germany) following the manufactory's protocol. In brief, $350 \mu \mathrm{L}$ of the cell lysates containing buffer RLT were input for extraction and purified RNAs were eluted in $50 \mu \mathrm{L}$ of RNase-free water. All RNAs extracted were then stored at $-80^{\circ} \mathrm{C}$ until use. Reverse transcription was performed to generate cDNA from total RNA by using the LunaScript®RT SuperMix Kit (BioLabs, New England). In brief, $16 \mu \mathrm{L}$ of the purified RNAs were mixed with the $4 \mu \mathrm{L}$ of the $5 \times$ reaction mix and incubated at $25^{\circ} \mathrm{C}$ for $2 \mathrm{~min}$ for primer annealing, followed by cDNA synthesis at $55^{\circ} \mathrm{C}$ for $10 \mathrm{~min}$ and enzyme inactivation at $95^{\circ} \mathrm{C}$ for $1 \mathrm{~min}$. cDNAs were then subsequently diluted in 1:20 with $1 \times$ TE buffer, pH 8.0 (Sigma-Aldrich, USA) and were kept at $-20{ }^{\circ} \mathrm{C}$ until use.

\subsection{Endogenous Control and Absolute Quantification by ddPCR}

The copy numbers of the viral genes and the endogenous RNase P were absolutely quantified in the ddPCR system. To co-amplify the viral genes and endogenous control (RNase P gene) in the same reaction, we applied duplex TaqMan probes for the ddPCR and labeled them with 6-FAM and VIC fluorescent signals respectively [16]. In brief, $20 \mu \mathrm{L}$ of a PCR reaction mix that contains $10 \mu \mathrm{L}$ of $2 \times$ ddPCR Supermix for Probes (No dUTP), $2 \mu \mathrm{L}$ of a primer/probe mixture (final concentration of each primer: approximately $900 \mathrm{nM}$; hydrolysis probe: approximately $250 \mathrm{nM}$ ), $3 \mu \mathrm{L}$ of 1:20 diluted cDNA, and $5 \mu \mathrm{L}$ of RNaseDNase-free water was prepared. The PCR reaction mix was then partitioned with droplet generation oil in a QX200 ${ }^{\mathrm{TM}}$ Droplet Generator for droplets generation. The partitioned products (roughly $40 \mu \mathrm{L}$ ) were then transferred to a new 96-well PCR plate $(0.2 \mathrm{~mL})$ and amplified in a C1000 Touch Thermo Cycler by using the following cycling conditions: enzyme activation at $95^{\circ} \mathrm{C}$ for $10 \mathrm{~min}$, followed by 40 cycles of a two-stage-amplification at $94{ }^{\circ} \mathrm{C}$ for $30 \mathrm{~s}$, at $60^{\circ} \mathrm{C}$ for $1 \mathrm{~min}$, and finally at $98^{\circ} \mathrm{C}$ for $10 \mathrm{~min}$. The partitioned droplets containing end-point fluorescent-labeled PCR products were then quantified immediately by QX200 Droplet Reader. Gating of the FAM/VIC counts was performed in QuantaSoft software according to the manufacturer instructions.

\subsection{Validation of the Primers and Probes on Clinical Specimens by RT-QPCR}

We selected 12 combined nasopharyngeal and throat swab clinical specimens that were previously laboratory confirmed as SARS-CoV-2-positive for the study. In brief, the viral RNA was extracted from $140 \mu \mathrm{L}$ of viral transport medium by using the QIAamp Viral RNA Kit (QIAGEN, Germany) that following the manufacturer's protocol and purified in $50 \mu \mathrm{L}$ of buffer AVE. The synthesis of cDNA was performed as described in Section 2.5. The cDNAs were then diluted in 1:10 with $1 \times$ TE buffer, pH 8.0 (Sigma-Aldrich, USA), and kept at $-20{ }^{\circ} \mathrm{C}$ until use. Quantitative real-time PCR was then performed by using the following sets of primers and probes: S, E, M, N, orf1a, orf1b, nsp1, nsp2, nsp3, nsp4, nsp5, nsp6, nsp7, nsp8, nsp9, nsp10, nsp12, nsp13, nsp14, nsp15, nsp16, orf3a, orf6, orf7a, orf7b, orf8, orf9b, orf10. Informed and written consents were obtained from all participants and the study was approved by the Medtimes Medical Group Ethics Review Board.

In brief, $10 \mu \mathrm{L}$ of reaction mix containing $5 \mu \mathrm{L}$ of $2 \times$ PerfeCTa qPCR ToughMix (Quantabio, USA); $1.5 \mu \mathrm{L}$ of primer and probe mixture that comprised $400 \mathrm{nM}$ each of the forward and reverse primers and $200 \mathrm{nM}$ each of the fluorescent hydrolysis probes; $3 \mu \mathrm{L}$ of 1:10 diluted cDNA; and $0.5 \mu \mathrm{L}$ of rox reference dye was prepared for each reaction. The qPCR reaction mix was then transferred to a $0.1 \mathrm{~mL} 96-$ well qPCR plate (Applied 
Biosystems, USA). The viral gene templates were amplified and the fluorescent signal was acquired by the ViiA 7 Real-Time PCR System (Thermo Fisher Scientific, USA) using the following cycling conditions: initial denaturation at $95^{\circ} \mathrm{C}$ for $1 \mathrm{~min}$, followed by 45 cycles of a two-stage amplification at $95^{\circ} \mathrm{C}$ for $2 \mathrm{~s}$ and at $60^{\circ} \mathrm{C}$ for $12 \mathrm{~s}$. QuantStudio ${ }^{\mathrm{TM}}$ Real-Time PCR Software v1.6.1 was then used for data analysis.

\subsection{Data and Statistical Analysis}

The one-way ANOVA statistics model was applied by using GraphPad Prism 9 (GraphPad Software Inc.) and the viral gene copies were normalized with endogenous mRNA control of ribonuclease P protein subunit p30 gene (RNase P gene). The absolute counting strategy is being enumerated and listed below, while FAM signal represented the target viral genes, VIC signal represented the endogenous control, and FAM/VIC heterogeneous signal reflected the droplets containing both signals and that were being co-amplified.

$$
\text { Viral RNA gene counts per copy of RNase P gene }=\frac{(\text { FAM })+(\text { FAM } / \text { VIC })}{(\text { VIC })+(\text { FAM } / \text { VIC })}
$$

To address the concern of amplification bias by using different primer/dual-labeled hydrolysis probe sets and resulting the counting discrimination, we additionally designed three sets of primers and probes on another conserve regions of nsp3 (B), S gene (B), and $\mathrm{N}$ gene (B). This aimed to determine the consistency of different primer/probe sets that targeting the same genes. Two-way ANOVA statistical analysis model was applied to assess the variations of primers and probes used. The difference was determined as significance when $p<0.05$.

\section{Results}

There are totally 16 nonstructural proteins (nsp 1 to 16 ), 4 structural proteins (S, E, M, and $\mathrm{N}$ ) and 10 accessory proteins (orf1a/ab, 3a/b, 6, 7a/b, 8, 9b, and 10) encoded by the viral genome of SARS-CoV-2 (Figure 1). To identify suitable target regions for the ddPCR, 61,013 of SARS-CoV-2 sequences were downloaded from GISAID and aligned. Twentyeight sets of primers and dual-labeled hydrolysis probes that targeting the conserved regions of different viral genes, including 4 structural proteins, 15 nonstructural proteins, and 9 accessory proteins, were designed (Table 1). The ddPCR for Nsp11 and orf3b genes were not included due to their short coding lengths. Oligos for the orf1a and orflab were designed to target the overlapping regions with nsp 2/3 and nsp 12/13 respectively. Additionally, two sets of primers and probes were designed to target to the $5^{\prime}$ and $3^{\prime}$ untranslated regions (UTR) respectively. To analyze the transcription pattern of subgenomic viral RNAs (sgRNA) and understand how the leader sequences are fused to the open reading frames, three additional sets of primers and probes were designed to target the (1) Leader-TRS, (2) Leader-TRS-N gene and (3) orf10-3' UTR respectively.

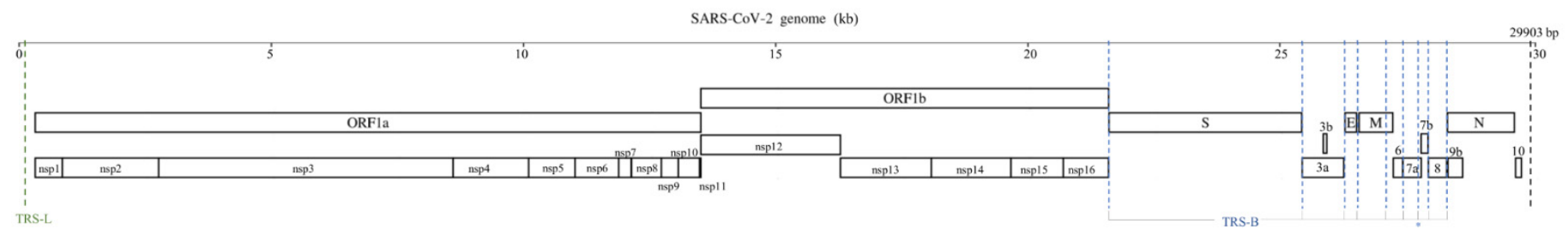

Figure 1. Genomic arrangement and coordinates of SARS-CoV-2. The encoding regions of different viral genes of SARSCoV-2 (29,903bp, NC_045512) are shown. There are 16 nonstructural proteins (nsps 1 to 16) encoded by orf1a and orf1b, 4 structural proteins (S, E, M, and N), and 8 accessory proteins (orf3a/b, 6, 7a/b, 8, 9b, and 10). The transcription regulatory sequences (TRS) that is located after the Leader sequences (TRS-L) is highlighted in green dash lines. The TRS that is located before each individual open reading frame (TRS-B) are highlighted in blue dash lines. 
Table 1. Primers and probes for ddPCR.

\begin{tabular}{|c|c|c|c|c|c|}
\hline Gene Categories & Target Regions & Primer/Probe & Sequence $\left(5^{\prime}\right.$ to $\left.3^{\prime}\right)$ & Position & Amplicon Size \\
\hline \multirow{12}{*}{$\begin{array}{l}\text { Structural } \\
\text { Proteins }\end{array}$} & \multirow[t]{3}{*}{$\mathrm{S}(\mathrm{A})$} & Forward & GTGACATCTCTGGCATTAATGC & \multirow[t]{3}{*}{$25062-25173$} & \multirow[t]{3}{*}{112} \\
\hline & & Reverse & CCAAGTTCTTGGAGATCGATGAG & & \\
\hline & & Probe & TGGCAACCTCATTGAGGCGGTC & & \\
\hline & \multirow[t]{3}{*}{ E } & Forward & GGTACGTTAATAGTTAATAGCGTAC & \multirow[t]{3}{*}{$26272-26395$} & \multirow[t]{3}{*}{124} \\
\hline & & Reverse & GACTCACGTTAACAATATTGCAG & & \\
\hline & & Probe & TCCTTACTGCGCTTCGATTGTGTG & & \\
\hline & \multirow[t]{3}{*}{ M } & Forward & GTGGACATCTTCGTATTGCTG & \multirow[t]{3}{*}{ 26959-27081 } & \multirow[t]{3}{*}{123} \\
\hline & & Reverse & CACGCTGCGAAGCTCCCAA & & \\
\hline & & Probe & CAACAGTGATTTCTTTAGGCAGGTCC & & \\
\hline & \multirow[t]{3}{*}{$\mathrm{N}(\mathrm{A})$} & Forward & GAAGTCACACCTTCGGGAAC & \multirow{3}{*}{$29240-29323$} & \multirow{3}{*}{84} \\
\hline & & Reverse & GACTTGATCTTTGAAATTTGGATCT & & \\
\hline & & Probe & TGGTTGACCTACACAGGTGCCATC & & \\
\hline & \multirow{3}{*}{ orf1a (nsp2-3) } & Forward & CССTTGCACCTAATATGATGG & $2667-2762$ & 96 \\
\hline & & Reverse & СТTCTATCACAGTGTCATCACC & & \\
\hline & & Probe & CTCAAAGGCGGTGCACCAACAAAG & & \\
\hline & orf1b (nsp12-13) & Forward & CACTTCAAGGTATTGGGAACC & $16173-16304$ & 132 \\
\hline & & Reverse & GGTCTACGTATGCAAGCACC & & \\
\hline & & Probe & CAGTCTTACAGGCTGTTGGGGCTT & & \\
\hline & nsp1 & Forward & TTCAACGAGAAAACACACGTCC & $287-407$ & 121 \\
\hline & & Reverse & CTTTAAGATGTTGACGTGCCTC & & \\
\hline & & Probe & CTTTGGAGACTCCGTGGAGGAGG & & \\
\hline & $\mathrm{nsp} 2$ & Forward & GTATTAACGGGCTTATGTTGCTC & $2616-2706$ & 91 \\
\hline & & Reverse & GTGAAGGTATTGTTTGTTACCATC & & \\
\hline & & Probe & CAGAAAAGTACTGTGCCСТTGCACC & & \\
\hline & nsp3 (A) & Forward & GACATAGAAGTTACTGGCGATAG & 8249-8367 & 119 \\
\hline & & Reverse & GCATTAATATGACGCGCACTAC & & \\
\hline & & Probe & CATGACACCCCGTGACCTTGG & & \\
\hline & nsp4 & Forward & GCTACAGAGAAGCTGCTTGTT & 9939-10051 & 113 \\
\hline & & Reverse & CAAAACAGCTGAGGTGATAGAG & & \\
\hline & & Probe & CATCAGAACCTGAGTTACTGAAGTC & & \\
\hline & nsp5 & Forward & GGAGTTCATGCTGGCACAGA & 10562-10685 & 124 \\
\hline & & Reverse & CAGCGTACAACCAAGCTAAAAC & & \\
\hline & & Probe & ACAAGCAGCTGGTACGGACACAAC & & \\
\hline & nsp6 & Forward & GTGTTATGTATGCATCAGCTGTAG & 11310-11404 & 95 \\
\hline & & Reverse & ATTCATAAGTGTCCACACTCTCC & & \\
\hline & & Probe & CACCATCATCATACACAGTTCTTGC & & \\
\hline & nsp7 & Forward & GTCAGATGTAAAGTGCACATCAG & 11851-11945 & 95 \\
\hline Nonstructural & & Reverse & ACTGGACACATTGAGCCCACA & & \\
\hline Proteins (NSP) & & Probe & CTCAGTTTTGCAACAACTCAGAGTAG & & \\
\hline & nsp8 & Forward & GGCTAAATCTGAATTTGACCGTG & $12223-12296$ & 74 \\
\hline & & Reverse & GGGTCATAGCTTGATCAGCC & & \\
\hline & & Probe & CCAACTTACGTTGCATGGCTGCA & & \\
\hline & nsp9 & Forward & CTAAGAGTGATGGAACTGGTAC & $12855-12938$ & 84 \\
\hline & & Reverse & CTTTAGGACCTTTAGGTGTGTCT & & \\
\hline & & Probe & CCTACAAGGTGGTTCCAGTTCTG & & \\
\hline & nsp10 & Forward & TGCTGTAGATGCTGCTAAAGCT & $13025-13169$ & 88 \\
\hline & & Reverse & TGTGTGTACACAACATCTTAACAC & & \\
\hline & & Probe & TGGTTGTCCCCCACTAGCTAGA & & \\
\hline & nsp12 & Forward & GTCATGTGTGGCGGTTCACT & 15439-15510 & 72 \\
\hline & & Reverse & AGCATAAGCAGTTGTGGCATC & & \\
\hline & & Probe & CCTGATGAGGTTCCACCTGGTTTAAC & & \\
\hline & nsp13 & Forward & CTATAGGTCCAGACATGTTCCTC & $17528-17602$ & 75 \\
\hline & & Reverse & CCAAAGCACTCACAGTGTCAAC & & \\
\hline & & Probe & CAGCAGGACAACGCCGACAAGTTC & & \\
\hline & nsp14 & Forward & GTATAACACGTTGCAATTTAGGTG & 19457-19604 & 148 \\
\hline & & Reverse & GTGTTCCAGAGGTTATAAGTATC & & \\
\hline & & Probe & TCAGCTGGCTTTAGCTTGTGGGTT & & \\
\hline & nsp15 & Forward & GCATTTGAGCTTTGGGCTAAGC & 19780-19861 & 82 \\
\hline & & Reverse & CAGCAATGTCCACACCCAAAT & & \\
\hline & & Probe & CAACATTAAACCAGTACCAGAGGTG & & \\
\hline & nsp16 & Forward & CAGGTACAGCTGTTTTAAGACAG & 20897-20977 & 81 \\
\hline & & Reverse & CATCAGAGACAAAGTCATTAAGATC & & \\
\hline & & Probe & CAGCGTACCCGTAGGCAACC & & \\
\hline
\end{tabular}


Table 1. Cont.

\begin{tabular}{|c|c|c|c|c|c|}
\hline Gene Categories & Target Regions & Primer/Probe & Sequence $\left(5^{\prime}\right.$ to $\left.3^{\prime}\right)$ & Position & Amplicon Size \\
\hline \multirow{21}{*}{$\begin{array}{c}\text { Accessory } \\
\text { Proteins }\end{array}$} & orf3a & Forward & CAAGGTGAAATCAAGGATGCTAC & $25441-25517$ & 77 \\
\hline & & Reverse & GGGAGTGAGGCTTGTATCGG & & \\
\hline & & Probe & CTTCAGATTTTGTTCGCGCTACTGC & & \\
\hline & orf6 & Forward & GTTTCATCTCGTTGACTTTCAGG & $27204-27289$ & 86 \\
\hline & & Reverse & CAAGATTCCAAATGGAAACTTTAAAAG & & \\
\hline & & Probe & CСTCATAATAATTAGTAATATCTCTGC & & \\
\hline & orf7a & Forward & GCTTTAGCACTCAATTTGCTTTTGC & $27566-27640$ & 75 \\
\hline & & Reverse & AAACTGATCTGGCACGTAACTG & & \\
\hline & & Probe & TGTCCTGACGGCGTAAAACACGTC & & \\
\hline & orf7b & Forward & GCTTTTTAGCCTTTCTGCTATTCC & $27790-27884$ & 95 \\
\hline & & Reverse & GGCGTGACAAGTTTCATTATGATC & & \\
\hline & & Probe & CTTTTGGTTCTCACTTGAACTGC & & \\
\hline & orf8 & Forward & CAGCACCTTTAATTGAATTGTGC & 28054-28193 & 140 \\
\hline & & Reverse & CACTACAAGACTACCCAATTTAGG & & \\
\hline & & Probe & CCCATTCAGTACATCGATATCGG & & \\
\hline & orf9b & Forward & CCCAATAATACTGCGTCTTGG & 28409-28492 & 84 \\
\hline & & Reverse & TGGAACGCCTTGTCCTCGAG & & \\
\hline & & Probe & CACCGCTCTCACTCAACATGGC & & \\
\hline & orf10 & Forward & TGGGCTATATAAACGTTTTCGCT & 29559-29642 & 84 \\
\hline & & Reverse & GTGCTATGTAGTTACGAGAATTC & & \\
\hline & & Probe & CCGTTTACGATATATAGTCTACTC & & \\
\hline \multirow{24}{*}{ Others } & Leader-TRS & Forward & TTAAAGGTTTATACCTTCCCAGG & $2-75$ & 74 \\
\hline & & Reverse & GTTCGTTTAGAGAACAGATCTAC & & \\
\hline & & Probe & AACAAACCAACCAACTTTCGATCTCT & & \\
\hline & $5^{\prime}$ UTR & Forward & GACAGGACACGAGTAACTCG & $155-229$ & 75 \\
\hline & & Reverse & TGCTGATGATCGGCTGCAAC & & \\
\hline & & Probe & CTGCAGGCTGCTTACGGTTTCG & & \\
\hline & $3^{\prime} \mathrm{UTR}$ & Forward & CACCACATTTTCACCGAGGC & 29719-29795 & 77 \\
\hline & & Reverse & CCATATAGGCAGCTCTCСC & & \\
\hline & & Probe & CTGTACACTCGATCGTACTCCGC & & \\
\hline & Leader-TRS-N & Forward & CCCAGGTAACAAACCAACCAAC & 19-28332 & $\mathrm{N} / \mathrm{A}$ \\
\hline & & Reverse & GGTCCACCAAACGTAATGCG & & \\
\hline & & Probe & ССССАAAATCAGCGAAATGCACC & & \\
\hline & orf10-3' UTR & Forward & GAATTCTCGTAACTACATAGCAC & $29620-29743$ & 124 \\
\hline & & Reverse & GCGTGGCCTCGGTGAAAATG & & \\
\hline & & Probe & CATTAGGGAGGACTTGAAAGAGCC & & \\
\hline & $\mathrm{S}(\mathrm{B})$ & Forward & GTTCTTGTGGATCCTGCTGC & $25305-25378$ & 74 \\
\hline & & Reverse & GTAATGTAATTTGACTCCTTTGAGC & & \\
\hline & & Probe & TGATGAAGACGACTCTGAGCCAG & & \\
\hline & $\mathrm{N}(\mathrm{B})$ & Forward & CTCATCACGTAGTCGCAACAG & $28831-28940$ & 110 \\
\hline & & Reverse & GCAGCAAAGCAAGAGCAGCA & & \\
\hline & & Probe & CCTGCTAGAATGGCTGGCAATGGC & & \\
\hline & nsp3 (B) & Forward & CGTTAAAGATTTCATGTCATTGTCTG & $8407-8513$ & 107 \\
\hline & & Reverse & CTTGTCTAGTAGTTGCACATGTC & & \\
\hline & & Probe & CTACGAAAACAAATACGTAGTGCTGCT & & \\
\hline \multirow{3}{*}{$\begin{array}{l}\text { Endogenous } \\
\text { Controls }\end{array}$} & RNase P & Forward & AGATTTGGACCTGCGAGCG & $28-114$ & 87 \\
\hline & & Reverse & GCAACAACTGAATAGCCAAGG & & \\
\hline & & Probe & TTCTGACCTGAAGGCTCTGCGCG & & \\
\hline
\end{tabular}

$\mathrm{S}(\mathrm{B}), \mathrm{N}(\mathrm{B})$, and nsp3(B): the alternative sets of primers/probes.

Human Caco-2 cells were infected by the SARS-CoV-2 and the total RNAs were collected at $15 \mathrm{~min}$, and 2, 4, 6, 8, 10, and $12 \mathrm{~h}$ postinfection. The transcription levels of the viral genes were determined by ddPCR using the corresponding primers and probe. In general, the kinetics of the viral transcription pattern were similar among all viral genes (Figure 2A-C). There was a significant decrease of the viral RNA level from the beginning of the infection to $2 \mathrm{~h}$ postinfection. No significant change of viral transcription was found from 2 to $6 \mathrm{~h}$ after infection, while dramatic increase of the viral RNA was observed beyond $6 \mathrm{~h}$ postinfection. Similarly to other coronaviruses, transcription of $\mathrm{N}$, Orf9b, and Orf10 were the most abundantly expressed among all viral genes encoded by the genome. This can be explained by the fact that their encoding regions are closer to the $3^{\prime}$ end of the viral genome than the other genes. Interestingly, we found no difference in the transcription among all NSP genes (Figure 2C). These results support that all the NSPs share one subgenome for their transcription. Reproducibility and performance of 
our ddPCR assays were further evaluated by using alternative sets of primers/probes that target different encoding regions of nsp3, N, and S. We showed that the alternative sets of primers / probes (nsp3 (B), N (B), and S(B)) did not lead to significant variation of our ddPCR results (Supplementary Figure S1).

A

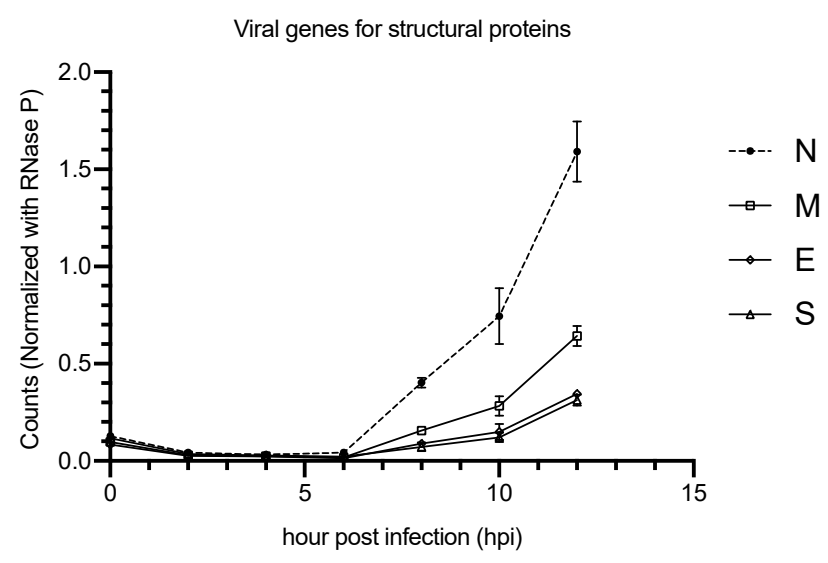

B

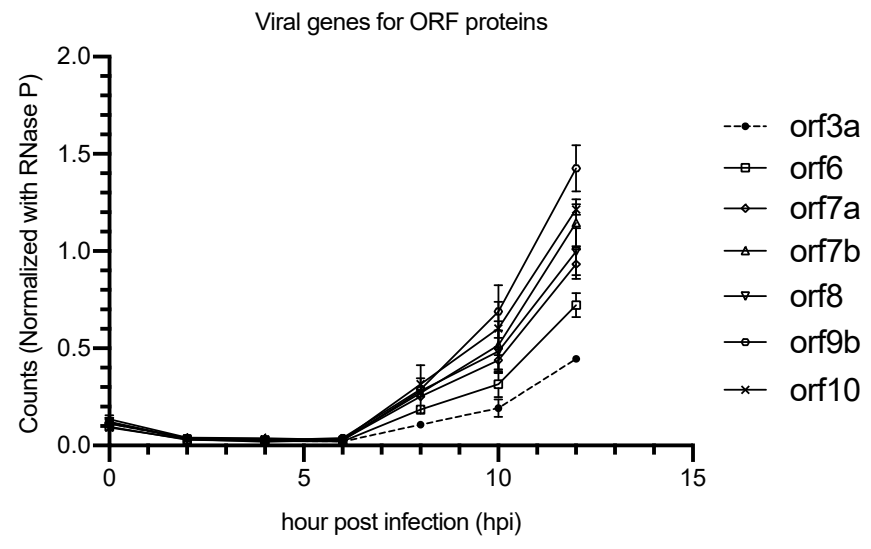

C

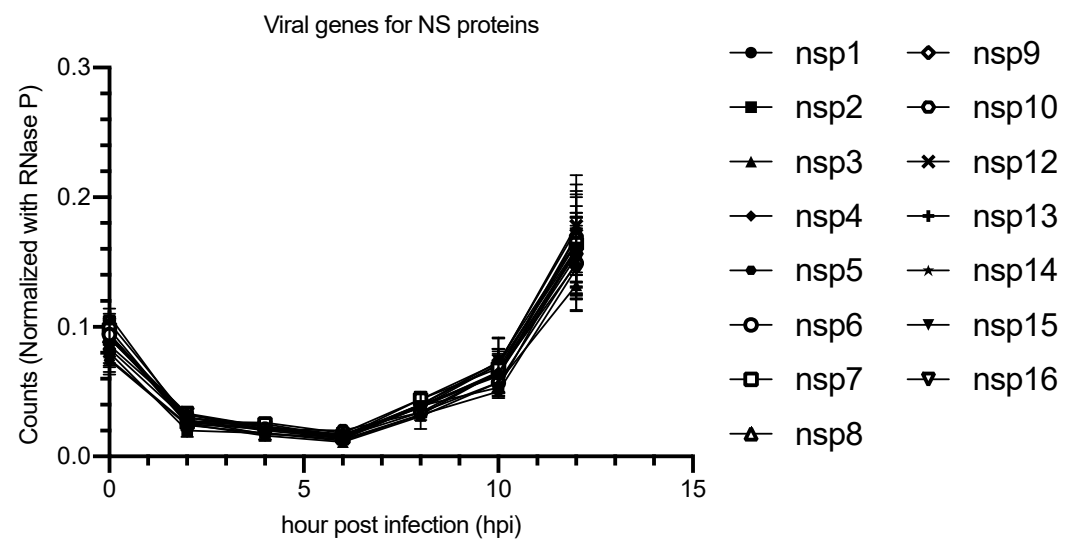

Figure 2. Transcription profiles of different viral genes of SARS-CoV-2 in Caco-2 cells. Human Caco-2 cells were infected by the SARS-CoV-2 at a moi of 0.01 and the total RNA was collected at 15 min (0), and $2,4,6,8,10$, and $12 \mathrm{~h}$ after infection. The transcription levels of the viral genes were determined by ddPCR using corresponding primers and probe. (A) Structural genes, (B) ORF genes, (C) NSP genes. All counts were normalized with endogenous control (RNase P gene). 
Discontinuous viral transcription process is a hallmark of coronavirus that produces a set of nested $3^{\prime}$ and $5^{\prime}$ co-terminal subgenomic RNAs for different viral genes. Since detection of $\mathrm{N}$ gene using our primer/probe set may also represent the subgenomic RNAs that are used for the transcription of other viral genes, we then sought to estimate the proportion of the $\mathrm{N}$ gene from the total transcription. We first determined the level of the total transcription from the infection using a primers/probe set which specifically targets the Leader-TRS region or $3^{\prime} \mathrm{UTR}$. The transcription that is specific for $\mathrm{N}$ gene was then detected by another set of primers / probe that covers the regions of Leader, TRS, and N. We found that about $38.1-39.6 \%$ and $53.4-56.7 \%$ among the total transcription involving the Leader-TRS and 3'UTR are specific for the transcription of N gene respectively (Figure 3A). Recently, a study reported that the protein expression of pp1a is 1.4-2.2 times higher than pp1ab. We found that the transcription levels of the ORF1a and ORF1b are similar, which support the hypothesis that the cause of the difference in the protein expression may be due to stoichiometry (Figure 3B).

A The transcription profile of genes with Leader-TRS or 3'UTR

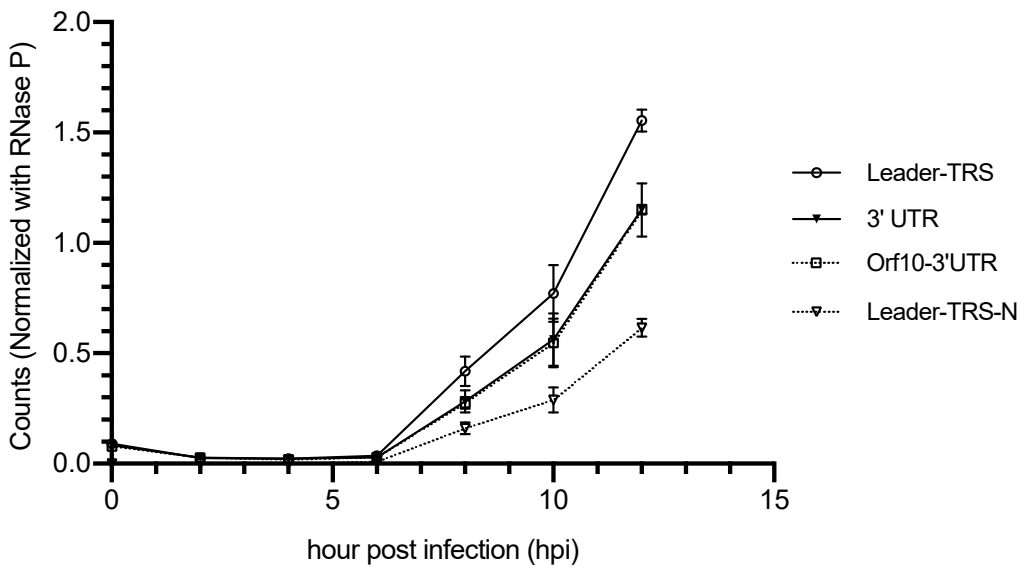

B The transcription profile at 5' end of viral RNA

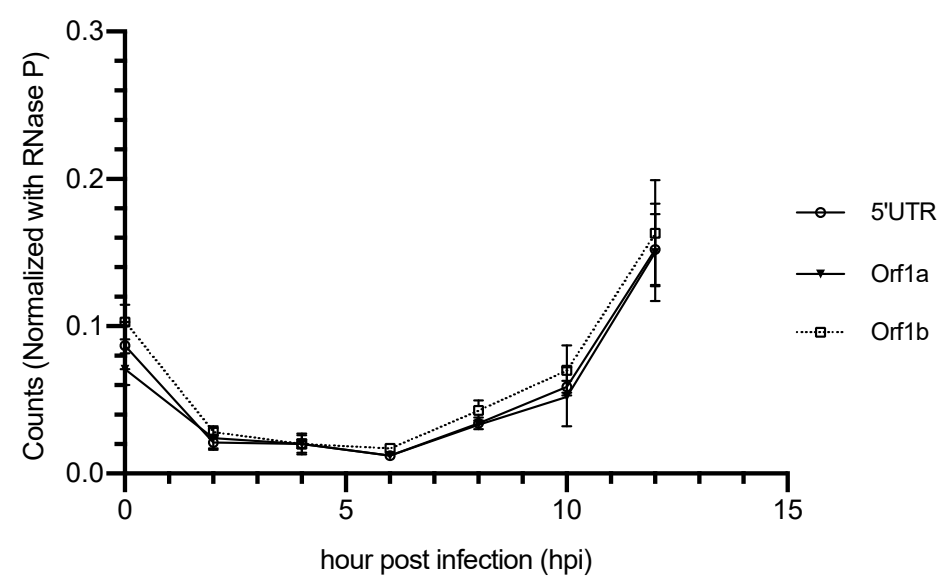

Figure 3. Transcription profiles at the $3^{\prime}$ and $5^{\prime}$ end of the viral RNA in Caco- 2 cells. Human Caco- 2 cells were infected by the SARS-CoV-2 at a moi of 0.01 and the total RNA was collected at $15 \mathrm{~min}(0)$, and $2,4,6,8,10$, and $12 \mathrm{~h}$ after infection. The transcription levels of the viral genes were determined by ddPCR using corresponding primers and probe. (A) The transcription quantification of the Leader-TRS, 3' UTR, Orf10-3' UTR and Leader-TRS-N. (B) The transcription quantification of orf1a (nsp2-3), orf1b (nsp12-13), and the $5^{\prime}$ UTR. All the counts were normalized with endogenous control (RNase P gene). 
To further determine the performance of the primers/probe, the expression levels of the structural, NSP, and ORF genes from 12 clinical swab specimens were tested by realtime qPCR (Table 2). All of the target genes were able to be amplified by our primers/probe and detected by the assay. Similarly to the results of our in vitro experiments, $\mathrm{N}$ and ORF9b genes showed the highest level of expression among all the target genes in each specimen.

Table 2. CT value of the clinical specimens using the primers and probe designed in this study.

\begin{tabular}{|c|c|c|c|c|c|c|c|c|c|c|c|c|}
\hline & \multicolumn{12}{|c|}{ Sample (CT Value) } \\
\hline & 1 & 2 & 3 & 4 & 5 & 6 & 7 & 8 & 9 & 10 & 11 & 12 \\
\hline$S$ & 14.6 & 16.9 & 15.9 & 25.1 & 24.5 & 25.8 & 26.6 & 26.4 & 19.5 & 16.6 & 15.7 & 13.7 \\
\hline E & 17.5 & 19.9 & 18.4 & 28.1 & 27.7 & 28.8 & 29.9 & 29.4 & 22.3 & 19.3 & 18.0 & 16.5 \\
\hline $\mathbf{M}$ & 17.7 & 19.6 & 19.1 & 27.8 & 26.1 & 29.0 & 29.8 & 29.5 & 22.3 & 19.5 & 18.8 & 16.9 \\
\hline $\mathbf{N}$ & 12.8 & 15.4 & 15.5 & 22.8 & 23.6 & 24.6 & 25.1 & 25.4 & 17.1 & 13.9 & 13.3 & 11.9 \\
\hline orf1a & 14.4 & 16.5 & 15.6 & 24.3 & 24.5 & 24.9 & 26.5 & 26.3 & 19.7 & 16.7 & 15.8 & 13.4 \\
\hline orf1b & 13.4 & 16.2 & 15.7 & 24.0 & 23.7 & 25.1 & 25.6 & 25.6 & 19.3 & 16.4 & 15.5 & 13.4 \\
\hline nsp1 & 14.0 & 16.6 & 15.6 & 24.4 & 24.2 & 25.6 & 26.0 & 26.4 & 19.8 & 16.9 & 16.0 & 13.7 \\
\hline nsp2 & 14.9 & 17.4 & 16.6 & 25.2 & 24.4 & 26.0 & 26.3 & 26.8 & 20.3 & 17.5 & 16.8 & 14.2 \\
\hline nsp3 & 14.8 & 17.2 & 16.7 & 24.9 & 23.7 & 26.0 & 26.0 & 26.6 & 19.9 & 17.3 & 16.4 & 13.9 \\
\hline nsp4 & 15.8 & 18.0 & 18.0 & 26.3 & 24.4 & 26.9 & 27.6 & 27.5 & 21.1 & 18.3 & 17.5 & 15.1 \\
\hline nsp5 & 15.4 & 18.0 & 18.1 & 25.6 & 24.4 & 26.8 & 27.6 & 27.8 & 21.1 & 18.4 & 17.6 & 15.2 \\
\hline nsp6 & 18.5 & 19.5 & 19.6 & 28.0 & 28.3 & 28.7 & 30.5 & 30.5 & 23.7 & 20.5 & 20.9 & 17.7 \\
\hline nsp7 & 15.5 & 17.6 & 16.8 & 25.4 & 24.5 & 25.9 & 27.2 & 26.9 & 20.9 & 17.9 & 17.3 & 15.0 \\
\hline nsp8 & 14.3 & 17.1 & 16.3 & 24.9 & 24.4 & 25.5 & 26.5 & 26.3 & 20.2 & 17.4 & 16.8 & 14.2 \\
\hline nsp9 & 15.0 & 17.4 & 16.6 & 25.4 & 25.2 & 26.3 & 26.8 & 27.3 & 20.6 & 17.9 & 17.3 & 14.7 \\
\hline nsp10 & 14.9 & 17.6 & 17.3 & 25.4 & 25.4 & 26.5 & 27.2 & 27.5 & 20.8 & 18.0 & 17.2 & 14.7 \\
\hline nsp12 & 14.9 & 17.7 & 17.4 & 25.6 & 25.0 & 26.2 & 27.1 & 26.5 & 20.5 & 18.1 & 17.5 & 14.8 \\
\hline nsp13 & 14.0 & 16.6 & 16.3 & 24.4 & 24.0 & 24.9 & 26.2 & 27.2 & 19.7 & 17.0 & 16.2 & 13.9 \\
\hline nsp14 & 14.1 & 16.8 & 16.6 & 24.5 & 24.2 & 25.4 & 26.2 & 26.2 & 19.8 & 17.0 & 16.2 & 13.9 \\
\hline nsp15 & 15.6 & 18.0 & 17.5 & 25.9 & 25.8 & 26.6 & 27.4 & 27.2 & 21.1 & 18.4 & 17.5 & 15.3 \\
\hline nsp16 & 13.6 & 16.4 & 15.9 & 24.2 & 23.5 & 24.6 & 25.8 & 25.4 & 19.4 & 16.4 & 15.6 & 13.6 \\
\hline orf3a & 15.3 & 17.3 & 15.6 & 25.1 & 25.6 & 25.8 & 27.4 & 27.4 & 19.5 & 16.5 & 15.8 & 13.9 \\
\hline orf6 & 16.8 & 18.9 & 18.0 & 27.2 & 28.1 & 28.9 & 29.9 & 29.6 & 21.0 & 18.1 & 17.7 & 15.6 \\
\hline orf7a & 13.3 & 16.2 & 15.4 & 24.0 & 24.5 & 25.2 & 26.2 & 25.8 & 18.3 & 15.0 & 14.4 & 12.7 \\
\hline orf7b & 13.8 & 15.9 & 14.8 & 23.9 & 24.3 & 25.1 & 25.9 & 25.6 & 17.9 & 14.8 & 14.6 & 12.3 \\
\hline orf8 & 14.2 & 16.5 & 15.2 & 24.1 & 24.6 & 25.3 & 26.5 & 25.9 & 20.2 & 17.2 & 16.5 & 14.9 \\
\hline orf9b & 12.8 & 14.7 & 13.9 & 22.6 & 23.5 & 23.7 & 25.3 & 24.8 & 15.7 & 12.9 & 13.0 & 10.6 \\
\hline orf10 & 16.0 & 17.9 & 16.9 & 25.7 & 27.3 & 27.2 & 29.2 & 28.5 & 19.8 & 16.4 & 16.0 & 14.6 \\
\hline
\end{tabular}

\section{Discussion}

Compared to traditional quantitative PCR (qPCR), ddPCR is a more sensitive assay for the detection of low levels of gene expression. Our ddPCR assays have the potential to be used for contact tracing so that COVID-19 patients can be identified during the early phase of their infections. The evolution of SARS-CoV-2 since the beginning of the outbreak has resulted in the emergence of variants of concern (VOCs) [15]. Some mutations such as the deletion at position 69/70del can cause a mismatch on the primer, which is used to target the $\mathrm{S}$ gene [15]. Moreover, the use of newly discovered drugs such as 
remdesivir or simeprevir may also cause escape mutations at the orf regions. Thus, these mutations may affect the accuracy of the diagnosis from detecting the viral nucleic acid. The primers and probes that we designed for detecting SARS-CoV-2 cover 15 NSP, 9 ORF, and 4 structural protein genes. All of them were designed and kept away from the highly variable positions of the SARS-CoV-2 genome and we expect that they may be useful for new variants detection in the coming future.

While the efficacy of remdesivir in humans is still suboptimal, structurally modification of this drug or identification of new compound will be one of the key directions for antiviral research. As we have demonstrated the kinetic of the transcription process of the SARS-CoV-2 in Caco-2 cells, our model may be useful for investigating the specific functions of new antiviral drugs such as delaying the incubation time before the initiation of viral transcription or reducing the transcription level, etc. Our study thus provides a model for evaluating the performance of any new antiviral drugs against the SARS-CoV-2 and their mechanism of action intensively.

The results from our infection model in human Caco-2 cells using digital droplet PCR assay has tracked the kinetic of the transcription profile of SARS-CoV-2 at the early cycle of replication. Although some studies also measured the transcription profile of this virus, primate origin cell lines, such as Vero cells, were used, which may not be physiologically relevant to the transcription property of SARS-CoV-2 in humans $[10,11]$. On the other hand, we traced the change of the viral transcription at every $2 \mathrm{~h}$ following $15 \mathrm{~min}$ after the infection. The results thus can provide a clear picture on how the viral transcription is being regulated during the first virus life cycle.

There was an obvious decrease of viral RNA at $2 \mathrm{~h}$ postinfection, suggesting that the input viral RNA was consumed for the translation after the entry step of SARS-CoV-2. It is known that the positive strand nature of the SARS-CoV-2 genomic RNA enables the virus to translate its own replicase-transcriptase-complex (RTC) by using host cell ribosomes [6]. Here, our data showed that SARS-CoV-2 requires about $6 \mathrm{~h}$ to hijack the host transcription machinery before it can further transcribe its subgenomic RNAs. We also found that there was absence of productive viral transcription in Caco-2 cells between 2 and $6 \mathrm{~h}$ postinfection. The study from Hofmann et al. showed that the viral transcription of bovine coronavirus (BCoV, beta-coronavirus) started at 3-4 $\mathrm{h}$ postinfection in human rectal tumor (HRT) cells [17]. The reason for the different transcription kinetics between the two coronaviruses will need to be further investigated. Moreover, it will be desirable to further explore the virology of the SARS-CoV-2 using primary lung epithelial cells or ex-vivo organoids.

\section{Conclusions}

In this study, we established $28 \mathrm{ddPCR}$ assays with specific primers/probe sets to detect the transcription profiles of 15 NSP, 9 ORF, and 4 structural protein genes of SARSCoV-2. The transcriptional kinetic of the viral genes of SARS-CoV-2 during the initial replication cycle in human cell was determined. We also found that SARS-CoV-2 takes around $6 \mathrm{~h}$ to hijack the cells before initiating a productive viral transcription process.

Supplementary Materials: The following are available online at https:/ / www.mdpi.com/article/10 .3390/pathogens10101274/s1, Figure S1: Primers and probes that designed on different conserve regions show no difference of results by ddPCR., Table S1-S3: The identified viral mutations and their occurrence frequencies of the structural proteins (Table S1), non-structural proteins (Table S2) and accessary proteins (Table S3).

Author Contributions: Conceptualization, C.K.P.M. and C.-K.C.; methodology, C.K.P.M. and C.-K.C.; validation, K.-K.A., C.C., C.K.P.M. and C.-K.C.; formal analysis, K.-K.A., C.C., C.K.P.M., Y.-M.C., W.W.S.W., H.L. and C.-K.C.; investigation, K.-K.A., C.C., C.K.P.M. and C.-K.C.; resources, C.K.P.M. and C.-K.C.; data curation, C.K.P.M. and C.-K.C.; writing-original draft preparation, C.K.P.M. and C.-K.C.; writing-review and editing, K.-K.A., H.L., C.K.P.M. and C.-K.C.; visualization, C.K.P.M. and C.-K.C.; supervision, C.K.P.M. and C.-K.C.; funding acquisition, C.K.P.M. and C.-K.C. All authors have read and agreed to the published version of the manuscript. 
Funding: This work is partially supported by Guangdong Province International Scientific and Technological Cooperation Projects (2020A0505100063), the National Research Foundation of Korea (NRF) grant funded through the Korea government (NRF-2018M3A9H4055203) and Calmette and Yersin scholarship from the Pasteur International Network Association (H.L.).

Institutional Review Board Statement: Informed and written consents were obtained from all participants and the study was approved by the Medtimes Medical Group Ethics Review Board.

Data Availability Statement: All data are reported in the manuscript and the supplementary materials.

Conflicts of Interest: K.K.A., Y.M.C., W.W.S.W. and C.K.C. are the employees of Medtimes Molecular Laboratory Limited, which is a privately-owned company in Hong Kong and provides SARS-CoV-2 diagnostic tests.

\section{References}

1. WHO Website. Available online: https://www.who.int/emergencies/diseases/novel-coronavirus-2019 (accessed on 26 August 2021).

2. Huang, C.; Wang, Y.; Li, X.; Ren, L.; Zhao, J.; Hu, Y.; Zhang, L.; Fan, G.; Xu, J.; Gu, X.; et al. Clinical features of patients infected with 2019 novel coronavirus in Wuhan, China. Lancet 2020, 395, 497-506. [CrossRef]

3. Guan, W.J.; Ni, Z.Y.; Hu, Y.; Liang, W.H.; Ou, C.Q.; He, J.X.; Liu, L.; Shan, H.; Lei, C.L.; Hui, D.S.C.; et al. China Medical Treatment Expert Group for Covid-19. Clinical Characteristics of Coronavirus Disease 2019 in China. N. Engl. J. Med. 2020, 382, 1708-1720. [CrossRef] [PubMed]

4. Mariano, G.; Farthing, R.J.; Lale-Farjat, S.L.M.; Bergeron, J.R.C. Structural Characterization of SARS-CoV-2: Where We Are, and Where We Need to Be. Front. Mol. Biosci. 2020, 7, 605236. [CrossRef] [PubMed]

5. Hui, K.P.Y.; Cheung, M.C.; Perera, R.A.P.M.; Ng, K.C.; Bui, C.H.T.; Ho, J.C.W.; Ng, M.M.T.; Kuok, D.I.T.; Shih, K.C.; Tsao, S.W.; et al. Tropism, replication competence, and innate i mMune responses of the coronavirus SARS-CoV-2 in human respiratory tract and conjunctiva: An analysis in ex-vivo and in-vitro cultures. Lancet. Respir. Med. 2020, 8, 687-695. [CrossRef]

6. V'kovski, P.; Kratzel, A.; Steiner, S.; Stalder, H.; Thiel, V. Coronavirus biology and replication: Implications for SARS-CoV-2. Nat. Rev. Microbiol. 2021, 19, 155-170. [CrossRef] [PubMed]

7. Wong, N.A.; Saier, M.H., Jr. The SARS-Coronavirus Infection Cycle: A Survey of Viral Membrane Proteins, Their Functional Interactions and Pathogenesis. Int. J. Mol. Sci. 2021, 22, 1308. [CrossRef] [PubMed]

8. Knoops, K.; Kikkert, M.; Worm, S.H.; Zevenhoven-Dobbe, J.C.; van der Meer, Y.; Koster, A.J.; Mo mMaas, A.M.; Snijder, E.J. Sars-coronavirus replication is supported by a reticulovesicular network of modified endoplasmic reticulum. PLoS Biol. 2008, 6, e226. [CrossRef] [PubMed]

9. Snijder, E.J.; Limpens, R.; de Wilde, A.H.; de Jong, A.W.M.; Zevenhoven-Dobbe, J.C.; Maier, H.J.; Faas, F.; Koster, A.J.; Barcena, M. A unifying structural and functional model of the coronavirus replication organelle: Tracking down rna synthesis. PLoS Biol. 2020, 18, e3000715. [CrossRef] [PubMed]

10. Telwatte, S.; Martin, H.A.; Marczak, R.; Fozouni, P.; Vallejo-Gracia, A.; Kumar, G.R.; Murray, V.; Lee, S.; Ott, M.; Wong, J.K.; et al. Novel RT-ddPCR assays for measuring the levels of subgenomic and genomic SARS-CoV-2 transcripts. Methods. 2021, 18, S1046-2023(21)00103-1. [CrossRef]

11. Telwatte, S.; Kumar, N.; Vallejo-Gracia, A.; Kumar, G.R.; Lu, C.M.; Ott, M.; Wong, J.K.; Yukl, S.A. Novel RT-ddPCR Assays for determining the transcriptional profile of SARS-CoV-2. J. Virol. Methods. 2021, 114115. [CrossRef] [PubMed]

12. Kim, D.; Lee, J.Y.; Yang, J.S.; Kim, J.W.; Kim, V.N.; Chang, H. The Architecture of SARS-CoV-2 Transcriptome. Cell 2021, 181, 914-921.e10. [CrossRef] [PubMed]

13. Taylor, S.C.; Laperriere, G.; Germain, H. Droplet Digital PCR versus qPCR for gene expression analysis with low abundant targets: From variable nonsense to publication quality data. Sci. Rep. 2017, 7, 2409. [CrossRef] [PubMed]

14. Kim, K.B.; Choi, H.; Lee, G.D.; Lee, J.; Lee, S.; Kim, Y.; Cho, S.Y.; Lee, D.G.; Kim, M. Analytical and Clinical Performance of Droplet Digital PCR in the Detection and Quantification of SARS-CoV-2. Mol. Diagn. Ther. 2021. In press.

15. Zella, D.; Giovanetti, M.; Benedetti, F.; Unali, F.; Spoto, S.; Guarino, M.; Angeletti, S.; Ciccozzi, M. The variants question: What is the problem? J. Med. Virol. 2021. In press. [CrossRef] [PubMed]

16. Nyaruaba, R.; Li, C.; Mwaliko, C.; Mwau, M.; Odiwuor, N.; Muturi, E.; Muema, C.; Xiong, J.; Li, J.; Yu, J.; et al. Developing multiplex ddPCR assays for SARS-CoV-2 detection based on probe mix and amplitude based multiplexing. Expert Rev. Mol. Diagn. 2021, 21, 119-129. [CrossRef] [PubMed]

17. Hofmann, M.A.; Sethna, P.B.; Brian, D.A. Bovine coronavirus mRNA replication continues throughout persistent infection in cell culture. J. Virol. 1990, 64, 4108-4114. [CrossRef] [PubMed] 